\title{
Natalizumab: Perspectives from the Bench to Bedside
}

\author{
Afsaneh Shirani ${ }^{1}$ and Olaf Stüve ${ }^{1,2}$ \\ ${ }^{1}$ Department of Neurology and Neurotherapeutics, University of Texas Southwestern Medical Center, Dallas, \\ Texas 75390 \\ ${ }^{2}$ Neurology Section, VA North Texas Health Care System, Medical Service Dallas, VA Medical Center, Dallas, \\ Texas 75216 \\ Correspondence: olaf.stuve@utsouthwestern.edu
}

\begin{abstract}
Probably no other disease-modifying drug for multiple sclerosis has a more fascinating story than natalizumab from both the bench to bedside perspective and the postmarketing experience standpoint. Natalizumab is a monoclonal antibody that inhibits the trafficking of lymphocytes from the blood into the central nervous system by blocking the adhesion molecule $\alpha 4$-integrin. Natalizumab was approved as a disease-modifying drug for relapsing remitting multiple sclerosis only 12 years after the discovery of its target molecule-a time line that is rather fast for drug development. However, a few months after its U.S. Food and Drug Administration approval, natalizumab was withdrawn from the market because of an unanticipated complication—progressive multifocal leukoencephalopathy. It was later reinstated with required adherence to a strict monitoring program and incorporation of mitigation strategies.
\end{abstract}

T he development of therapeutic monoclonal antibodies shows the importance of a targetcentered approach to modify the course of multiple sclerosis (MS) (Buttmann and Rieckmann 2008). Natalizumab is the first monoclonal antibody approved for the treatment of relapsing MS after convincingly showing clinically and radiologically significant effects in phase III trials (Stüve and Bennett 2007). In this review, we highlight the evolution of natalizumab from bench to bedside, summarize findings from pivotal clinical trials of natalizumab, and discuss the relevant adverse effects, particularly multifocal leukoencephalopthy, lessons learned from risk mitigation strategies, as well as several other aspects related to natalizumab use in clinical practice.

\section{DISCOVERY AND MECHANISM OF ACTION}

Natalizumab (Tysabri, Biogen Idec, Cambridge, $\mathrm{MA}$ ) is a humanized recombinant immunoglobulin (Ig)G4 monoclonal antibody that blocks the $\alpha 4$-integrin-mediated leukocyte-endothelial interaction, resulting in inhibition of trafficking of lymphocytes from the blood into the central nervous system (CNS) (Stüve and Bennett 2007). The discovery of the target molecule for natalizumab dates back to 1992 (Yednock et al. 1992); however, the interaction be-

Editors: Howard L. Weiner and Vijay K. Kuchroo

Additional Perspectives on Multiple Sclerosis available at www.perspectivesinmedicine.org

Copyright (C) 2018 Cold Spring Harbor Laboratory Press; all rights reserved; doi: 10.1101/cshperspect.a029066

Cite this article as Cold Spring Harb Perspect Med 2018;8:a029066 
tween endothelium and lymphocytes has been studied since the mid-1960s when it was first shown in rats that lymphocytes enter lymph nodes through specialized blood vessels called high endothelial venules (Gowans and Knight 1964). Later, in the 1980s and early 1990s, several studies focused on the mapping of molecules involved in the process of lymphocyte migration, highlighting the role of integrins and selectins, particularly the cellular adhesion molecules, including intracellular adhesion molecule (ICAM) and vascular cell adhesion molecule (VCAM) (Osborn et al. 1989; Springer 1994; Butcher and Picker 1996). The integrin very-late-activating antigen 4 ( $\alpha 4 \beta 1$-integrin; VLA- 4 ) was identified as a receptor for VCAM-1, and the VCAM1/VLA-4 ligand-receptor pair was suggested to play a major role in the recruitment of mononuclear leukocytes to inflammatory sites in vivo (Elices et al. 1990). In an attempt to further identify the adhesion receptors involved in lymphocyte homing to inflamed brain endothelium, scientists at Stanford University and Athena Neurosciences collaborated on investigating this question in the animal model of MS, experimental autoimmune encephalomyelitis (EAE) (Yednock et al. 1992). Using an in vitro adhesion assay on frozen sections of EAE, they showed that lymphocytes and monocytes selectively bind to the lumen of the vessels, consistent with an endothelial interaction. They found that this binding was blocked by antibodies against the $\alpha 4$-integrin molecule and not by antibodies against numerous alternative adhesion receptors (Yednock et al. 1992). This finding was followed by an in vivo experiment in which administration of antibodies to $\alpha 4$-integrin to EAE rats ameliorated the paralysis and prevented the accumulation of leukocytes in the CNS as evidenced by immunohistochemical studies of brains from EAE rats. This was the first study providing direct evidence to suggest that therapies based on interfering with $\alpha 4 \beta 1$-integrin may be useful in treating inflammatory disease of the CNS such as MS (Yednock et al. 1992). The expression of adhesion molecules VLA-4 and VCAM-1 was later shown in an MS autopsy brain using immunohistochemical analysis (Verbeek et al. 1995). These studies led to the first phase I safety and pharmacokinetic study of a humanized $\alpha 4$-integrin antibody, natalizumab (Antegren, Athena Neurosciences, South San Francisco, CA) (Sheremata et al. 1999).

\section{EARLY CLINICAL STUDIES}

A phase I, randomized, placebo-controlled, fivelevel dose-escalation trial of a single IV dose of natalizumab (with doses ranging from 0.03 to $3.0 \mathrm{mg} / \mathrm{kg}$ ), showed that all tested doses were safe and well tolerated, and justified further trials (Sheremata et al. 1999). An open-label safety and drug interaction study of natalizumab in combination with interferon (IFN)- $\beta$-1a in 38 patients with MS provided safety and tolerability data to support efficacy trials of combination therapy (Vollmer et al. 2004). A phase II, randomized, double-blind, placebo-controlled trial of natalizumab in 72 patients with active relapsing MS showed a significant reduction in the number of new active lesions on magnetic resonance imaging (MRI) over the first 12 weeks of the study, but no significant difference in the second 12 weeks of the study (Tubridy et al. 1999). Another phase II trial aimed at assessing the effect of a single dose of IV natalizumab (vs. placebo) soon after the onset of relapses in 180 patients with MS (O'Connor et al. 2004). This study showed that natalizumab did not hasten clinical recovery after relapse; however, a significant decrease in the volume of enhancing lesion volume was noted at 1 and 3 weeks after treatment (O'Connor et al. 2004). Another important phase II trial assessed the efficacy of two doses of monthly natalizumab $(3 \mathrm{mg} / \mathrm{kg}$ and 6 $\mathrm{mg} / \mathrm{kg}$ ) versus placebo for 6 months, followed by a 6-month observation (Miller et al. 2003). The study showed that both of the tested doses of natalizumab led to fewer inflammatory brain lesions and fewer relapses over a 6-month period in patients with relapsing MS (Miller et al. 2003).

\section{PIVOTAL CLINICAL TRIALS}

The two pivotal phase III trials of natalizumab in patients with relapsing forms of MS include AFFIRM (Natalizumab Safety and Efficacy in Relapsing Remitting Multiple Sclerosis) and SEN- 
TINEL (Safety and Efficacy of Natalizumab in Combination with IFN- $\beta-1 a$ in Patients with Relapsing Remitting Multiple Sclerosis) studies (Polman et al. 2006; Rudick et al. 2006). In the AFFIRM study, the efficacy and safety of natalizumab as a monotherapy in relapsing remitting MS patients was investigated, whereas the SENTINEL study was designed to evaluate the efficacy and safety of natalizumab in combination with intramuscular IFN- $\beta$-1a (Avonex).

In the AFFIRM study, a total of 942 patients were randomly assigned in a 2:1 ratio to receive intravenous natalizumab $300 \mathrm{mg}$ (627 patients) or placebo (315 patients) every 4 weeks for up to 116 weeks (Polman et al. 2006). The inclusion criteria required patients ages 18 to 50 years, diagnosis of relapsing remitting MS, a baseline-Expanded Disability Status Scale (EDSS) score of $\leq 5$, at least one relapse within the 12 months before the study, and MRI lesions consistent with MS. The primary end points were the rate of clinical relapses at 1 year, and rate of sustained disability progression as measured by EDSS at 2 years. Secondary end points at 1 year included the number of new or enlarging T2hyperintense lesions, the number of gadolinium-enhancing lesions, and the proportion of relapse-free patients. Secondary end points at 2 years included the rate of clinical relapse, the volume of T2 lesions, the number of new T1 hypointense lesions, and disability progression as measured by the Multiple Sclerosis Functional Composite. The median disease duration was 5 years. Natalizumab monotherapy significantly reduced the rate of clinical relapse at 1 year by $68 \%$ and the risk of sustained disability progression at 2 years by $42 \%$ compared with placebo, accumulation of new or enlarging hyperintense T2 lesions at 2 years by $83 \%$, and the number of gadolinium-enhancing lesions by $92 \%$ at both 1 and 2 years. The proportion of relapse-free patients at 2 years in the natalizumab group was $67 \%$ (vs. $41 \%$ in the placebo group, $p<0.001$ ) (Polman et al. 2006).

In the SENTINEL trial, a total of 1171 patients, who despite IFN- $\beta$ - 1 a therapy had at least one relapse during the 12-month period before the study, were randomly assigned in a 1:1 ratio to receive continued intramuscular IFN- $\beta$ - $1 \mathrm{a}$ in combination with natalizumab $300 \mathrm{mg}$ (589 patients) or placebo (582 patients) intravenously every 4 weeks for up to 116 weeks (Rudick et al. 2006). Similar to the AFFIRM study, inclusion criteria included patients ages 18 to 50 years, diagnosis of relapsing remitting MS, a baseline EDSS score of $\leq 5$, at least one relapse within the 12 months before the study, and MRI lesions consistent with MS. Primary and secondary end points were also defined identical to the AFFIRM study. The similar inclusion criteria and end-point definition allowed clinically useful conclusions to be drawn from these two studies. Combination therapy with natalizumab was associated with 55\% relative reduction in annulized relapse rate $(0.34 \%$ compared with $0.75 \%$ with IFN- $\beta$ - 1 a), $83 \%$ reduction in the number of new or enlarging T2 lesions at 2 years, $89 \%$ reduction in the number of the gadolinium-enhancing lesions, and $24 \%$ reduction in relative risk of sustained disability progression at 2 years (Rudick et al. 2006).

Later, in a phase II, randomized, doubleblind, placebo-controlled trial called Glatiramer Acetate and Natalizumab Combination Evaluation (GLANCE), safety and tolerability of combination therapy with natalizumab added to glatiramer acetate (GA) was compared to GA only (Goodman et al. 2009). The incidence of infection and infusion reactions was similar in both groups, and no hypersensitivity reactions were reported. It was concluded that the combination of natalizumab and GA seemed safe and well tolerated during 6 months of therapy (Goodman et al. 2009).

\section{PROGRESSIVE MULTIFOCAL LEUKOENCEPHALOPATHY}

In February 2005, only about 3 months after its first approval, natalizumab was voluntarily withdrawn from the market by its manufacturers, Biogen Idec and Elan Corporation (Dublin, Ireland). This decision followed the observation of three cases of progressive multifocal leukoencephalopathy (PML). Two patients developed PML in the SENTINEL trial in which they received natalizumab in combination with IFN- $\beta$-1a (Kleinschmidt-DeMasters and Tyler 
2005; Langer-Gould et al. 2005). The third patient received natalizumab in a clinical trial of Crohn's disease (Van Assche et al. 2005). Given that approximately 3000 individuals had been treated with natalizumab at that time, the risk of developing PML with natalizumab use was estimated at 1 in 1000 (Berger and Koralnik 2005).

PML is a rare but life-threatening demyelinating disease of the CNS caused by infection of oligodendrocytes by John Cunningham virus (JCV), a human polyomavirus that was named after the initials of the patient from whom it was first isolated in 1971 (Berger and Houff 2006). Approximately half of the world's population is already infected by JCV by age 20 and perhaps as many as $70 \%$ by late age. JCV infection almost never causes symptoms in immunocompetent individuals (Berger and Khalili 2011). PML is strongly associated with immunosuppressed status and predominantly occurs in patients with acquired immune deficiency syndrome (AIDS); however, it has been reported with monoclonal antibodies and various other immunosuppressants.

Postmarketing studies of natalizumab showed that median treatment duration to onset of PML symptoms was 25 months (range: 6-80 months) (Clifford et al. 2010). The most common presenting symptoms included changes in cognition, personality, and motor function, and less commonly seizures (Clifford et al. 2010). Clinical suspicion of PML should warrant discontinuation of natalizumab, acquisition of MRI, and assessment of JCV in the cerebrospinal fluid (CSF). Management of natalizumab associated PML requires plasma exchange or immunoabsorption to hasten removal of natalizumab and to reestablish immune surveillance of the CNS (Khatri et al. 2009). Paradoxically, the effective clearance of natalizumab and restoration of immune surveillance may result in worsening of neurologic deficits and MRI lesions, consistent with the development of immune reconstitution inflammatory syndrome (IRIS), a potentially life-threatening complication (Tan et al. 2011). Corticosteroid therapy provides a modest benefit in natalizumab-associated PML-IRIS (Tan et al. 2011). Recently, punctuate pattern of MRI lesions has been suggested as a useful imaging feature in a presymptomatic stage of PML (Hodel et al. 2016).

Natalizumab was later reintroduced to the market in June 2006, and approved by the Food and Drug Administration (FDA) for highly active MS, with a black box warning regarding risk of PML, and with required adherence to a special restricted distribution program developed by the FDA known as TOUCH (Tysabri Outreach Unified Commitment to Health) aimed at minimizing the risks of use of natalizumab.

\section{RISK MITIGATION}

Postmarketing analyses have identified three factors (alone or in combination) that contribute to the risk of natalizumab-associated PML: (1) positive serostatus for anti-JCV antibodies, (2) prior exposure to immunosuppressants, and (3) increased duration of natalizumab therapy (Gorelik et al. 2010; Bloomgren et al. 2012). Serum levels of anti-JCV antibody, measured as index, may help in further defining the risk of PML in anti-JCV, antibody-positive MS patients with no prior immunosuppressant use who are treated with natalizumab (Plavina et al. 2014). Table 1 shows the estimated risk of PML associated with natalizumab use depending on these three factors (Berger and Fox 2016a, 2016b). Based on these factors and associated risk estimates, mitigation strategies need to be incorporated. The JCV antibody serology status needs to be checked at least every 6 months. In case of seroconversion, the risk-benefit profile of natalizumb treatment should be revisited.

If any clinical suspicion for PML exists, the patient should be promptly evaluated even if their JCV antibody serostatus is negative (Ontaneda and Fox 2013). Patients who are JCV antibody negative with a previous history of exposure to immunosuppressants are usually tested for JCV antibody status every 3 months. JCV antibody seroconversion may be accelerated in patients treated with natalizumab. A recent study estimated a seroconversion rate of $8.5 \%$ $10.3 \%$ per year in natalizumab-treated patients (Schwab et al. 2016). 
Table 1. Estimated risk of PML associated with natalizumab use $\mathrm{a}^{\mathrm{a}}$

\begin{tabular}{lccc}
\hline & & \multicolumn{2}{c}{ Anti-JCV antibody positive } \\
\cline { 3 - 4 } Anti-JCV antibody & $\begin{array}{c}\text { Duration of exposure to } \\
\text { natalizumab (months) }\end{array}$ & No prior & Prior immunosuppressant \\
& 1 to $<24$ & $<1 / 1000$ & use \\
\hline$<1 / 1000$ & $\geq 24$ & $8: 1000$ & $2.5: 1000$ \\
& negative & & $23: 1000$ \\
\hline
\end{tabular}

PML, Progressive multifocal leukoencephalopathy; JCV, John Cunningham virus.

${ }^{\mathrm{a}}$ Based on Berger and Fox (2016b).

Although the risk stratification identified factors that can prevent PML in patients with MS under natalizumab, its introduction into clinical practice has not been a success with regard to its intended purpose. The rate of natalizumab-associated PML has not only not decreased (Cutter and Stüve 2014), but the latest data published by Berger and Fox indicate that the absolute number of cases and the relative risk of PML have actually doubled (Berger and Fox 2016a, 2016b). The reason for this failure of risk stratification is not completely understood. It certainly appears that many neurologists may have difficulties interpreting the risk-stratification algorithm. The primary focus may be on the JCV serostatus when assessing the overall risk of natalizumab-associated PML, and neglecting other risk factors. For instance, prior pharmacological immunosuppression increases PML susceptibility in patients who at the time of natalizumab initiation are JCV negative, but subsequently seroconvert without being identified as seroconverters. Also, the duration of natalizumab therapy is a major risk modifier that should not be ignored, but that may be difficult to monitor in daily clinical practice. Finally, disease reactivation observed after cessation of natalizumab (see below) may lead to reluctance in patients and care providers to discontinue natalizumab even if the risk of PML is considered high. Effective sequential pharmacotherapies following natalizumab need to be identified.

\section{OTHER ADVERSE EFFECTS}

Although the main safety concern with natalizumab is the development of PML, other aspects of natalizumab safety merit attention. In the AFFIRM trial, overall the most common side effects associated with the treatment were headache, fatigue, and infections in both the natalizumab and placebo groups. The adverse events that were significantly more common in the natalizumab group were fatigue and allergic reaction. Infections occurred at a rate of 1.52 per patient/year in the natalizumab group and 1.42 per patient/year in the placebo group without any significant difference. Infections were generally mild-to-moderate in severity and did not result in drug discontinuation. Common infections included nasopharyngitis, influenza, respiratory tract infections, and urinary tract infections. Serious infections occurred in $3.2 \%$ of patients in the natalizumab group versus $2.6 \%$ of patients in the placebo group. The most common serious infections in the natalizumab group included pneumonia and urosepsis. The most common serious adverse event was relapse of MS in $6 \%$ of patients with natalizumab and $13 \%$ with placebo. Infusion-related reactions (defined as symptoms within $2 \mathrm{~h}$ after the start of drug administration) were significantly more common in the natalizumab group (24\%) versus the placebo group (18\%). The most common infusion-related reaction was headache. Most reactions were managed with symptomatic treatment and did not lead to discontinuation of the medication. Hypersensitivity reactions requiring discontinuation of natalizumab occurred in $4 \%$ of patients and included urticaria, allergic dermatitis, and anaphylactic or anaphylactoid reactions (Polman et al. 2006).

In the SENTINEL trial, the most common side effects in both the natalizumab combination therapy group and IFN- $\beta$-1a-only group were headache and nasopharyngitis. Adverse events that were significantly associated with natalizumab combination therapy included anxi- 
ety, pharyngitis, sinus congestion, and peripheral edema. The most common serious adverse event was relapse of the disease in $5 \%$ of patients in the natalizumab combination therapy group and $9 \%$ of patients in the IFN- $\beta$-1a group. Infections occurred at a rate of 1.54 per patient/ year with combination therapy and 1.53 per patient/year with IFN- $\beta$-1a. Common infections included nasopharyngitis, urinary tract infection, sinusitis, and upper respiratory tract infection. Infusion-related reactions occurred more frequently in the combination therapy group ( $24 \%$ vs. $20 \%$ in the placebo group), although the difference was not statistically significant. Similar to the AFFIRM trial, the most common infusion-related reaction was headache, and most reactions did not result in discontinuation of the medication. Hypersensitivity reactions occurred in $1.9 \%$ of patients in the combination therapy group (Rudick et al. 2006).

There were more cases of cancer in the natalizumab group in the AFFIRM trial (five cases) compared with one case in the placebo group. The five cases of cancer among natalizumabtreated patients included three cases of breast cancer, one case of cervical cancer (stage 0), and one case of newly diagnosed metastatic melanoma (Polman et al. 2006). There has also been other case reports of melanoma in MS patients treated with natalizumab (Bergamaschi and Montomoli 2009; Laroni et al. 2011); however, it is debatable whether this is a casual association versus merely a coincidence. Long-term prospective data and pharmacovigilance programs are warranted to investigate the risk of cancer with natalizumab use.

There are rare reports of clinically significant hepatic injury in association with natalizumab use. Monitoring liver function is therefore required (Dubey et al. 2016), and natalizumab should be discontinued in patients with evidence of liver injury (Bezabeh et al. 2010).

\section{DISEASE REACTIVATION AFTER CESSATION OF NATALIZUMAB}

Although natalizumab is a highly effective treatment for active MS, some patients need to discontinue the treatment to reduce the risk of
PML, or for other reasons such as pregnancy. Several lines of evidence from pivotal clinical trials and case series indicate the return of disease activity once natalizumab is stopped. Although some studies suggest no dramatic increase in disease activity 6 months or 14 months after treatment cessation (Miller et al. 2003; Stüve et al. 2009), others believe that a rebound may in fact occur (Vellinga et al. 2008; Larochelle et al. 2016). A post hoc analysis of patients who received natalizumab in AFFIRM, SENTINEL, and GLANCE trials before suspension in 2005, including monthly follow-up for 8 months after cessation of natalizumab, showed that despite an increase in disease activity after 3 months, the average disease activity did not exceed the pretreatment level (O'Connor et al. 2011), a finding that indicates possible lack of rebound. It is still possible that a subgroup of patients may be more susceptible to show highly active disease after discontinuation of natalizumab therapy (Schaaf et al. 2011). It has recently been suggested that assessment of the T helper (Th)17-cell/interleukin (IL)-17 axis might help to predict rebound MS activity after natalizumab cessation (Haas et al. 2016).

\section{ANTI-IDIOTYPIC ANTIBODIES}

In the AFFIRM study, antibodies against natalizumab were detected in $9 \%$ of patients who received natalizumab monotherapy with $3 \%$ classified as transiently positive and $6 \%$ as persistently positive (defined as positive result on at least two visits that were 6 weeks apart) (Polman et al. 2006). In the SENTINEL study, $12 \%$ of patients treated with natalizumab combined with IFN- $\beta$-1a developed anti-natalizumab antibodies; with 6\% classified as persistently positive (Rudick et al. 2006). Patients with persistently positive antibodies to natalizumab were found to have loss of clinical efficacy as measured by relapse rate, disability progression, and MRI activity compared with antibody-negative patients (Calabresi et al. 2007). These patients also had an increase in infusion-related adverse events (Polman et al. 2006; Rudick et al. 2006). However, in patients with transiently positive patients, efficacy was achieved after 
about 6 months of treatment when patients' antibody status became negative (Calabresi et al. 2007). It is therefore recommended that patients with ongoing disease activity or persistent infusion-related adverse events while being treated with natalizumab be tested for antibodies against natalizumab (Calabresi et al. 2007; Fox et al. 2007).

\section{PREGNANCY}

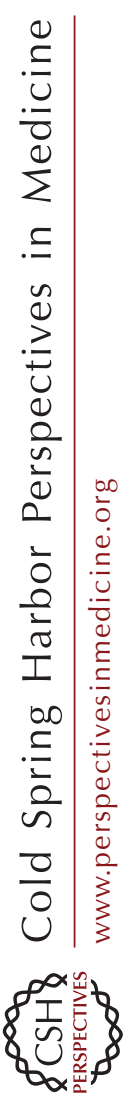

There are no studies on the effects of natalizumab on human fertility (Amato and Portaccio 2015); however, $\alpha 4$-integrins and their ligands are believed to be widely involved in mammalian development (Wehner et al. 2009). Natalizumab is classified as pregnancy level $\mathrm{C}$ by the FDA. Women treated with natalizumab are therefore recommended to use adequate contraception or stop natalizumab 3 months before conception. However, there exists a risk of accidental fetal exposure to disease-modifying therapies in women of childbearing age.

In a prospective controlled observational study of 102 pregnancies in women exposed to natalizumab during the first trimester of pregnancy as compared with 95 pregnancies in disease-matched women and 98 pregnancies in healthy control subjects, natalizumab did not appear to increase the baseline risk of malformations in comparison with disease-matched patients (Ebrahimi et al. 2015). The mean birth weight and length were significantly less compared to healthy control subjects $(3159 \mathrm{~g}$ and $50.3 \mathrm{~cm}$, respectively) but comparable to those observed in disease-matched patients. The rate of spontaneous abortion, however, was significantly higher in exposed pregnancies (17.3\%) and in disease-matched patients $(21.1 \%)$ compared to healthy control subjects (4.1\%) (Ebrahimi et al. 2015). In another prospective observational study of 35 women with MS who became accidentally pregnant while being treated with natalizumab, 29 women delivered 28 healthy children, one child was born with hexadactyly, five pregnancies ended in an early miscarriage, and one woman decided to undergo an elective termination of pregnancy (Zohren et al. 2008). Although these data may suggest that elective termination of pregnancy because of natalizumab exposure may not be necessary, women should still be advised to stop natalizumab in the course of planned pregnancy until more long-term data become available.

Mild-to-moderate hematological alterations (mainly thrombocytopenia and anemia) have been reported in 10 of 13 infants whose mothers received natalizumab during the third trimester of pregnancy (Haghikia et al. 2014).

Excretion of natalizumab into breast milk has been reported (Baker et al. 2015). Although natalizumab is not orally bioavailable, it is still recommended to avoid natalizumab during lactation.

\section{OBSERVATIONAL STUDIES}

Long-term observational studies are crucial in defining the best practice in the use of natalizumab for MS. So far, a number of observational studies have confirmed the effectiveness of natalizumab in clinical practice (Mancardi et al. 2011; Piehl et al. 2011; Fernandez et al. 2012), with some studies even reporting a greater reduction in disease activity to the active treatment arm of the AFFIRM trial (Fernandez 2013; Totaro et al. 2014). There are two large, ongoing observational studies of natalizumab, including STRATA (Safety of Tysabri Redosing and Treatment) and TOP (Tysabri Observational Program) (Planas et al. 2014). STRATA is a long-term (up to 10 years), open-label, multinational, follow-up study of natalizumab monotherapy in patients who completed the AFFIRM, SENTINEL, and GLANCE trials and their open-label extensions (O'Connor et al. 2014). TOP is a 10-year prospective, open-label, postmarketing observational study of the longterm safety and efficacy of natalizumab in clinical practice settings in Europe, Australia, Canada, and Argentina (Butzkueven et al. 2014). Interim analysis of both studies confirm natalizumab's overall safety profile and showed that treatment with natalizumab consistently lowers annualized relapse rates and stabilizes EDSS scores (Butzkueven et al. 2014; O'Connor et al. 2014). 


\section{COST EFFECTIVENESS}

With the emergence of novel oral and infusion treatments for MS, there is a need for real-world cost-effectiveness evaluation of disease-modifying drugs. The annual cost of natalizumab when it was first approved in the United States in November 2004 was $\$ 25,850$, more than $50 \%$ higher than IFN- $\beta$ and GA (Hartung et al. 2015). As with several other disease-modifying drugs, natalizumab cost has increased over time, estimated at $\$ 64,233$ in 2013 (Hartung et al. 2015). Yet, several studies support favorable cost-effectiveness for natalizumab compared with other disease-modifying treatments such as IFN- $\beta$, GA, and fingolimod in terms of cost per relapse avoided (Gani et al. 2008; Chiao and Meyer 2009; O’Day et al. 2011).

\section{CONCLUDING REMARKS}

The development of natalizumab, its bench-tobedside story, and the lessons learned from its postmarketing experience highlight both the value of a molecular-targeted approach and the risks of unexpected adverse events associated with novel biological therapeutics. Although natalizumab remains a highly effective therapy for relapsing forms of MS, there remains more to be learned with respect to its long-term safety profile.

\section{COMPETING INTEREST STATEMENT}

A.S. has no disclosures. O.S. serves on the editorial boards of JAMA Neurology, Multiple Sclerosis Journal, and Therapeutic Advances in Neurological Disorders. O.S. has served on datamonitoring committees for Pfizer and SanofiAventis without monetary compensation. O.S. collaborated with Medscape on educational initiatives. O.S. represented Novartis in front of a Scientific Advisory Group at the European Medicines Agency (EMA). O.S. has advised Genentech and Sanofi-Aventis. O.S. has participated in a Teva-sponsored meeting. O.S. has consulted for Huron Life Sciences and Navigant Consulting. O.S. received travel support from Pfizer.

\section{ACKNOWLEDGMENTS}

O.S. currently receives grant support from Teva Pharmaceuticals and Opexa Therapeutics. O.S. is funded by a Merit grant from the U.S. Department of Veterans Affairs.

\section{REFERENCES}

Amato MP, Portaccio E. 2015. Fertility, pregnancy and childbirth in patients with multiple sclerosis: Impact of disease-modifying drugs. CNS Drugs 29: 207-220.

Baker TE, Cooper SD, Kessler L, Hale TW. 2015. Transfer of natalizumab into breast milk in a mother with multiple sclerosis. J Hum Lact 31: 233-236.

Bergamaschi R, Montomoli C. 2009. Melanoma in multiple sclerosis treated with natalizumab: Causal association or coincidence? Mult Scler 15: 1532-1533.

Berger JR, Fox RJ. 2016a. Erratum to: Reassessing the risk of natalizumab-associated PML. J Neurovirol 22: 536-537.

Berger JR, Fox RJ. 2016b. Reassessing the risk of natalizumab-associated PML. J Neurovirol 22: 533-535.

Berger JR, Houff S. 2006. Progressive multifocal leukoencephalopathy: Lessons from AIDS and natalizumab. Neurol Res 28: 299-305.

Berger JR, Khalili K. 2011. The pathogenesis of progressive multifocal leukoencephalopathy. Discov Med 12: $495-$ 503.

Berger JR, Koralnik IJ. 2005. Progressive multifocal leukoencephalopathy and natalizumab-Unforeseen consequences. N Engl J Med 353: 414-416.

Bezabeh S, Flowers CM, Kortepeter C, Avigan M. 2010. Clinically significant liver injury in patients treated with natalizumab. Aliment Pharmacol Ther 31: 1028-1035.

Bloomgren G, Richman S, Hotermans C, Subramanyam M, Goelz S, Natarajan A, Lee S, Plavina T, Scanlon JV, Sandrock A, et al. 2012. Risk of natalizumab-associated progressive multifocal leukoencephalopathy. $N$ Engl J Med 366: $1870-1880$

Butcher EC, Picker LJ. 1996. Lymphocyte homing and homeostasis. Science 272: 60-66.

Buttmann M, Rieckmann P. 2008. Treating multiple sclerosis with monoclonal antibodies. Expert Rev Neurother 8: 433-455.

Butzkueven H, Kappos L, Pellegrini F, Trojano M, Wiendl H, Patel RN, Zhang A, Hotermans C, Belachew S; Tysabri Observational Program Investigators. 2014. Efficacy and safety of natalizumab in multiple sclerosis: Interim observational programme results. J Neurol Neurosurg Psychiatry 85: 1190-1197.

Calabresi PA, Giovannoni G, Confavreux C, Galetta SL, Havrdova E, Hutchinson M, Kappos L, Miller DH, O'Connor PW, Phillips JT, et al. 2007. The incidence and significance of anti-natalizumab antibodies: Results from AFFIRM and SENTINEL. Neurology 69: 13911403.

Chiao E, Meyer K. 2009. Cost effectiveness and budget impact of natalizumab in patients with relapsing multiple sclerosis. Curr Med Res Opin 25: 1445-1454. 
Clifford DB, De Luca A, Simpson DM, Arendt G, Giovannoni G, Nath A. 2010. Natalizumab-associated progressive multifocal leukoencephalopathy in patients with multiple sclerosis: Lessons from 28 cases. Lancet Neurol 9: 438-446.

Cutter GR, Stüve O. 2014. Does risk stratification decrease the risk of natalizumab-associated PML? Where is the evidence? Mult Scler 20: 1304-1305.

Dubey D, Cano CA, Stüve O. 2016. Update on monitoring and adverse effects of approved second-generation disease-modifying therapies in relapsing forms of multiple sclerosis. Curr Opin Neurol 29: 278-285.

Ebrahimi N, Herbstritt S, Gold R, Amezcua L, Koren G, Hellwig K. 2015. Pregnancy and fetal outcomes following natalizumab exposure in pregnancy. A prospective, controlled observational study. Mult Scler 21: 198-205.

Elices MJ, Osborn L, Takada Y, Crouse C, Luhowskyj S, Hemler ME, Lobb RR. 1990. VCAM-1 on activated endothelium interacts with the leukocyte integrin VLA-4 at a site distinct from the VLA-4/fibronectin binding site. Cell 60: $577-584$.

Fernandez O. 2013. Best practice in the use of natalizumab in multiple sclerosis. Ther Adv Neurol Disord 6: 69-79.

Fernandez O, Oreja-Guevara C, Arroyo R, Izquierdo G, Perez JL, Montalban X. 2012. Natalizumab treatment of multiple sclerosis in Spain: Results of an extensive observational study. J Neurol 259: 1814-1823.

Fox EJ, Vartanian TK, Zamvil SS. 2007. The immunogenicity of disease-modifying therapies for multiple sclerosis: Clinical implications for neurologists. Neurologist 13: 355-362.

Gani R, Giovannoni G, Bates D, Kemball B, Hughes S, Kerrigan J. 2008. Cost-effectiveness analyses of natalizumab (Tysabri) compared with other disease-modifying therapies for people with highly active relapsing-remitting multiple sclerosis in the UK. Pharmacoeconomics 26: 617-627.

Goodman AD, Rossman H, Bar-Or A, Miller A, Miller DH, Schmierer K, Lublin F, Khan O, Bormann NM, Yang M, et al. 2009. GLANCE: Results of a phase 2, randomized, double-blind, placebo-controlled study. Neurology 72: 806-812.

Gorelik L, Lerner M, Bixler S, Crossman M, Schlain B, Simon K, Pace A, Cheung AA, Chen LL, Berman M, et al. 2010. Anti-JC virus antibodies: Implications for PML risk stratification. Ann Neurol 68: 295-303.

Gowans JL, Knight EJ. 1964. The route of re-circulation of lymphocytes in the rat. Proc R Soc Lond B Biol Sci 159: 257-282.

Haas J, Schneider K, Schwarz A, Korporal-Kuhnke M, Faller S, von Glehn F, Jarius S, Wildemann B. 2016. Th17 cells: A prognostic marker for MS rebound after natalizumab cessation? Mult Scler 23: 114-118.

Haghikia A, Langer-Gould A, Rellensmann G, Schneider H, Tenenbaum T, Elias-Hamp B, Menck S, Zimmermann J, Herbstritt S, Marziniak M, et al. 2014. Natalizumab use during the third trimester of pregnancy. JAMA Neurol 71: 891-895.

Hartung DM, Bourdette DN, Ahmed SM, Whitham RH 2015. The cost of multiple sclerosis drugs in the US and the pharmaceutical industry: Too big to fail? Neurology 84: 2185-2192.
Hodel J, Darchis C, Outteryck O, Verclytte S, Deramecourt V, Lacour A, Zins M, Pruvo JP, Vermersch P, Leclerc X. 2016. Punctate pattern: A promising imaging marker for the diagnosis of natalizumab-associated PML. Neurology 86: 1516-1523.

Khatri BO, Man S, Giovannoni G, Koo AP, Lee JC, Tucky B, Lynn F, Jurgensen S, Woodworth J, Goelz S, et al. 2009. Effect of plasma exchange in accelerating natalizumab clearance and restoring leukocyte function. Neurology 72: 402-409.

Kleinschmidt-DeMasters BK, Tyler KL. 2005. Progressive multifocal leukoencephalopathy complicating treatment with natalizumab and interferon $\beta$-1a for multiple sclerosis. N Engl J Med 353: 369-374.

Langer-Gould A, Atlas SW, Green AJ, Bollen AW, Pelletier D. 2005. Progressive multifocal leukoencephalopathy in a patient treated with natalizumab. N Engl J Med 353: 375381.

Larochelle C, Metz I, Lecuyer MA, Terouz S, Roger M, Arbour N, Bruck W, Prat A. 2016. Immunological and pathological characterization of fatal rebound MS activity following natalizumab withdrawal. Mult Scler 23: 72-81.

Laroni A, Bedognetti M, Uccelli A, Capello E, Mancardi GL. 2011. Association of melanoma and natalizumab therapy in the Italian MS population: A second case report. Neurol Sci 32: 181-182.

Mancardi GL, Tedeschi G, Amato MP, D'Alessandro R, Drago F, Milanese C, Popoli P, Rossi P, Savettieri G, Tola MR, et al. 2011. Three years of experience: The Italian registry and safety data update. Neurol Sci 31: 295297.

Miller DH, Khan OA, Sheremata WA, Blumhardt LD, Rice GP, Libonati MA, Willmer-Hulme AJ, Dalton CM, Miszkiel KA, O'Connor PW, et al. 2003. A controlled trial of natalizumab for relapsing multiple sclerosis. $N$ Engl J Med 348: 15-23.

O'Connor PW, Goodman A, Willmer-Hulme AJ, Libonati MA, Metz L, Murray RS, Sheremata WA, Vollmer TL, Stone LA; Natalizumab Multiple Sclerosis Trial Group. 2004. Randomized multicenter trial of natalizumab in acute MS relapses: Clinical and MRI effects. Neurology 62: 2038-2043.

O'Connor PW, Goodman A, Kappos L, Lublin FD, Miller DH, Polman C, Rudick RA, Aschenbach W, Lucas N. 2011. Disease activity return during natalizumab treatment interruption in patients with multiple sclerosis. Neurology 76: 1858-1865.

O’Connor P, Goodman A, Kappos L, Lublin F, Polman C, Rudick RA, Hauswirth K, Cristiano LM, Forrestal F, Duda P. 2014. Long-term safety and effectiveness of natalizumab redosing and treatment in the STRATA MS Study. Neurology 83: 78-86.

O’Day K, Meyer K, Miller RM, Agarwal S, Franklin M. 2011. Cost-effectiveness of natalizumab versus fingolimod for the treatment of relapsing multiple sclerosis. J Med Econ 14: 617-627.

Ontaneda D, Fox RJ. 2013. Multiple sclerosis treatment: Risk mitigation. Continuum (Minneap Minn) 19: 1092-1099.

Osborn L, Hession C, Tizard R, Vassallo C, Luhowskyj S, Chi-Rosso G, Lobb R. 1989. Direct expression cloning of vascular cell adhesion molecule 1, a cytokine-induced 
A. Shirani and O. Stüve

endothelial protein that binds to lymphocytes. Cell 59: 1203-1211.

Piehl F, Holmen C, Hillert J, Olsson T. 2011. Swedish natalizumab (Tysabri) multiple sclerosis surveillance study. Neurol Sci 31: 289-293.

Planas R, Martin R, Sospedra M. 2014. Long-term safety and efficacy of natalizumab in relapsing-remitting multiple sclerosis: Impact on quality of life. Patient Relat Outcome Meas 5: 25-33

Plavina T, Subramanyam M, Bloomgren G, Richman S, Pace A, Lee S, Schlain B, Campagnolo D, Belachew S, Ticho B. 2014. Anti-JC virus antibody levels in serum or plasma further define risk of natalizumab-associated progressive multifocal leukoencephalopathy. Ann Neurol 76: 802812.

Polman CH, O'Connor PW, Havrdova E, Hutchinson M, Kappos L, Miller DH, Phillips JT, Lublin FD, Giovannoni G, Wajgt A, et al. 2006. A randomized, placebo-controlled trial of natalizumab for relapsing multiple sclerosis. $N$ Engl J Med 354: 899-910.

Rudick RA, Stuart WH, Calabresi PA, Confavreux C, Galetta SL, Radue EW, Lublin FD, Weinstock-Guttman B, Wynn DR, Lynn F, et al. 2006. Natalizumab plus interferon $\beta$-1a for relapsing multiple sclerosis. $N$ Engl J Med 354: 911923.

Schaaf SM, Pitt D, Racke MK. 2011. What happens when natalizumab therapy is stopped? Expert Rev Neurother 11: 1247-1250.

Schwab N, Schneider-Hohendorf T, Pignolet B, Breuer J, Gross CC, Gobel K, Brassat D, Wiendl H. 2016. Therapy with natalizumab is associated with high JCV seroconversion and rising JCV index values. Neurol Neuroimmunol Neuroinflamm 3: e195.

Sheremata WA, Vollmer TL, Stone LA, Willmer-Hulme AJ, Koller M. 1999. A safety and pharmacokinetic study of intravenous natalizumab in patients with MS. Neurology 52: 1072-1074.

Springer TA. 1994. Traffic signals for lymphocyte recirculation and leukocyte emigration: The multistep paradigm. Cell 76: 301-314.

Stüve O, Bennett JL. 2007. Pharmacological properties, toxicology and scientific rationale for the use of natalizumab (Tysabri) in inflammatory diseases. CNS Drug Rev 13: 79-95.

Stüve O, Cravens PD, Frohman EM, Phillips JT, Remington GM, von Geldern G, Cepok S, Singh MP, Tervaert JW,
De Baets M, et al. 2009. Immunologic, clinical, and radiologic status 14 months after cessation of natalizumab therapy. Neurology 72: 396-401.

Tan IL, McArthur JC, Clifford DB, Major EO, Nath A. 2011. Immune reconstitution inflammatory syndrome in natalizumab-associated PML. Neurology 77: 1061-1067.

Totaro R, Lugaresi A, Bellantonio P, Danni M, Costantino G, Gasperini C, Florio C, Pucci E, Maddestra M, Spitaleri D, et al. 2014. Natalizumab treatment in multiple sclerosis patients: A multicenter experience in clinical practice in Italy. Int J Immunopathol Pharmacol 27: 147-154.

Tubridy N, Behan PO, Capildeo R, Chaudhuri A, Forbes R, Hawkins CP, Hughes RA, Palace J, Sharrack B, Swingler $\mathrm{R}$, et al. 1999. The effect of anti- $\alpha 4$ integrin antibody on brain lesion activity in MS. The UK Antegren Study Group. Neurology 53: 466-472.

Van Assche G, Van Ranst M, Sciot R, Dubois B, Vermeire S, Noman M, Verbeeck J, Geboes K, Robberecht W, Rutgeerts P. 2005. Progressive multifocal leukoencephalopathy after natalizumab therapy for Crohn's disease. NEngl $J$ Med 353: 362-368

Vellinga MM, Castelijns JA, Barkhof F, Uitdehaag BM, Polman CH. 2008. Postwithdrawal rebound increase in T2 lesional activity in natalizumab-treated MS patients. Neurology 70: 1150-1151.

Verbeek MM, Westphal JR, Ruiter DJ, de Waal RM. 1995. T lymphocyte adhesion to human brain pericytes is mediated via very late antigen-4/vascular cell adhesion molecule-1 interactions. J Immunol 154: 5876-5884.

Vollmer TL, Phillips JT, Goodman AD, Agius MA, Libonati MA, Giacchino JL, Grundy JS. 2004. An open-label safety and drug interaction study of natalizumab (Antegren) in combination with interferon- $\beta$ (Avonex) in patients with multiple sclerosis. Mult Scler 10: 511-520.

Wehner NG, Shopp G, Rocca MS, Clarke J. 2009. Effects of natalizumab, an $\alpha 4$ integrin inhibitor, on the development of Hartley guinea pigs. Birth Defects Res B Dev Reprod Toxicol 86: 98-107.

Yednock TA, Cannon C, Fritz LC, Sanchez-Madrid F, Steinman L, Karin N. 1992. Prevention of experimental autoimmune encephalomyelitis by antibodies against $\alpha 4 \beta 1$ integrin. Nature 356: 63-66.

Zohren F, Toutzaris D, Klarner V, Hartung HP, Kieseier B, Haas R. 2008. The monoclonal anti-VLA-4 antibody natalizumab mobilizes $\mathrm{CD} 34^{+}$hematopoietic progenitor cells in humans. Blood 111: 3893-3895. 


\section{$\&_{\mathrm{CSH}}^{\infty} \&$ Cold Spring Harbor

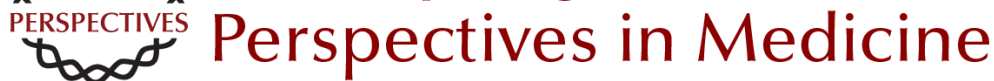

\section{Natalizumab: Perspectives from the Bench to Bedside}

Afsaneh Shirani and Olaf Stüve

Cold Spring Harb Perspect Med 2018; doi: 10.1101/cshperspect.a029066 originally published online March 2, 2018

\section{Subject Collection Multiple Sclerosis}

\section{Multiple Sclerosis Pathology}

Hans Lassmann

Regulatory T Cells: From Discovery to

Autoimmunity

Alexandra Kitz, Emily Singer and David Hafler

The Multiple Roles of B Cells in Multiple Sclerosis and Their Implications in Multiple Sclerosis

Therapies

Rui Li and Amit Bar-Or

Autologous Hematopoietic Stem Cell

Transplantation in the Treatment of Multiple

Sclerosis

Carolina A. Rush, Harold L. Atkins and Mark S.

Freedman

B-Cell Therapies in Multiple Sclerosis Joseph J. Sabatino, Jr., Scott S. Zamvil and Stephen L. Hauser

Oral Therapies for Multiple Sclerosis Simon Faissner and Ralf Gold

Interferon $\beta$ for Multiple Sclerosis

Dejan Jakimovski, Channa Kolb, Murali

Ramanathan, et al.

Alemtuzumab as Treatment for Multiple Sclerosis Serafeim Katsavos and Alasdair Coles

\author{
Natalizumab: Perspectives from the Bench to \\ Bedside \\ Afsaneh Shirani and Olaf Stüve \\ Daclizumab Therapy for Multiple Sclerosis \\ Bibiana Bielekova
}

\section{Lifestyle and Environmental Factors in Multiple \\ Sclerosis \\ Lars Alfredsson and Tomas Olsson \\ Biomarkers in Multiple Sclerosis \\ Anu Paul, Manuel Comabella and Roopali Gandhi}

The Evolving Mechanisms of Action of Glatiramer

Acetate

Thomas Prod'homme and Scott S. Zamvil

Regulation of Astrocyte Functions in Multiple Sclerosis

Michael A. Wheeler and Francisco J. Quintana

Experimental Autoimmune Encephalomyelitis

(EAE) as Animal Models of Multiple Sclerosis (MS)

Simon Glatigny and Estelle Bettelli

Neurodegeneration in Progressive Multiple

Sclerosis

Graham Campbell and Don Mahad

For additional articles in this collection, see http://perspectivesinmedicine.cshlp.org/cgi/collection/ 